\title{
DCLK1 as a Promising Marker for Radioresistance in Colorectal Cancer
}

\author{
Chiman Mohammadi ${ }^{1} \cdot$ Rezvan Najafi $^{1}$ (D)
}

Published online: 17 August 2019

(C) Springer Science+Business Media, LLC, part of Springer Nature 2019
Colorectal cancer (CRC) is considered third in terms of frequency and second regarding of mortality, where it has been estimated, over 1.8 million new colorectal cancer cases and 881,000 deaths occurred in 2018 [1]. It has been accepted that radiation therapy (RT) is a highly efficient method of cancer therapy by which DNA damage in tumor cells inhibits their capacity to divide and proliferate more [2]. Nevertheless, in spite of available new therapeutic techniques, a high number of patients still suffer relapse, largely as a result of intrinsic resistance of tumor cells to radiation. Hence, it is crucial to elucidate the causative mechanism(s) and develop new therapeutic strategies to improve the radiosensitivity of CRC cells [3]. Accordingly, novel therapeutic radiosensitizers are urgently needed for overcoming tumor radioresistance and thus improving the outcome of radiotherapy [4].

Doublecortin-like kinase 1 (DCLK1) is a microtubuleassociated protein kinase where marks pancreatic and intestinal stem cells. DCLK1 as an important prognostic marker is involved in normal nervous system development and overexpressed in numerous cancers such as the colon, pancreas, kidney, liver, and esophagus [5]. Cumulative evidence proofs that DCLK1 expression plays a critical role in controlling of several key oncogenes (e.g., c-MYC, KRAS, NOTCH, NFKB, and WNT) involving in cancer stem cells, metastasis, EMT, and cancer cell growth/self-renewal $[6,7]$. This provides a basis for DCLK1 as a key regulator for initiation and progression of solid tumors as well as its correlation with chemo-/radiotherapy resistance [8-10].

A number of studies suggested that inhibition of DCLK1 results in suppression and sensitization of tumor cells to radioand chemotherapy [10-12]. In $A p c^{\mathrm{Min} /+}$ mice model, siRNAmediated knockdown of DCLK1, caused in tumor growth arrest, regression of intestinal polyps and downregulation of

Rezvan Najafi

re.najafi@umsha.ac.ir; najafi2535@gmail.com

1 Research Center for Molecular Medicine, Hamadan University of Medical Sciences, Hamadan, Iran pluripotency factors and EMT-associated transcriptional factors of intestinal epithelial cells [13]. Study by Chandracesan et al. (2016) showed that DCLK1 expression in tuft cells via paracrine mechanisms and activation of ATM-mediated DNA-damage response (DDR) promoted intestinal epithelial radio-resistance and self-renewal/survival. On the other hand, loss of DCLK1 expression in tuft cells led to an increase in crypt apoptosis and reduction in pluripotency factors, ATM, gamma-H2AX, and other adaptors in HR repair, after exposure to radiation [11]. In addition, Ji et al. (2018) revealed that miR-15b by targeting DCLK1 not only repress self-renewal and tumorigenicity of $\mathrm{CRC}$, but also improves sensitivity of cancer cells to chemo/radiotherapy [8]. Recently, it was shown that Niclosamide (an FDA-approved anthelmintic drug) prevents lymphoid enhancer-binding factor 1 (LEF1)-mediated transcription of DCLK1 and this led to attenuate cancer stemness and sensitizes CRC to chemoradiation [14]. Taken together, it seems that inhibition of DCLK1 restores the radiosensitivity of cancer cells and provides a novel target for the treatment of CRC. Nevertheless, the molecular mechanism by which silencing DCLK1 mediates the radiosensitivity in colorectal cancer is not elucidated well.

In conclusion, we hypothesized that DCLK1 nhibition could serve as a candidate therapeutic target to reverse radioresistance in CRC, thus, if the results confirm our hypothesis, DCLK1 might be a promising therapeutic target to improve the response of CRC to radiation therapy.

\section{Compliance with Ethical Standards}

Conflict of Interest The authors declare that they have no conflict of interest.

\section{References}

1. Bray F, Ferlay J, Soerjomataram I, Siegel RL, Torre LA, Jemal A. Global cancer statistics 2018: GLOBOCAN estimates of incidence and mortality worldwide for 36 cancers in 185 countries. CA Cancer J Clin. 2018;68(6):394-424. 
2. Baskar R, Lee KA, Yeo R, Yeoh K-W. Cancer and radiation therapy: current advances and future directions. Int J Med Sci. 2012;9(3):193-9.

3. Wu T, Lin B, Chang H, Chang C. Radio resistance mechanisms of cancers: an overview and future perspectives. Biol Med S. 2015;2: 2.

4. Kim B, Hong Y, Lee S, Liu P, Lim J, Lee Y, et al. Therapeutic implications for overcoming radiation resistance in cancer therapy. Int J Mol Sci. 2015;16(11):26880-913.

5. Chandrakesan P, Yao J, Qu D, May R, Weygant N, Ge Y, et al. Dclk1, a tumor stem cell marker, regulates pro-survival signaling and self-renewal of intestinal tumor cells. Mol Cancer. 2017;16(1): 30.

6. Chandrakesan P, Panneerselvam J, Qu D, Weygant N, May R, Bronze M, et al. Regulatory roles of Dclk1 in epithelial mesenchymal transition and cancer stem cells. J Carcinog Mutagen. 2016;7(2).

7. Sureban SM, May R, Qu D, Weygant N, Chandrakesan P, Ali N, et al. DCLK1 regulates pluripotency and angiogenic factors via microRNA-dependent mechanisms in pancreatic cancer. PLoS One. 2013;8(9):e73940.

8. Ji D, Zhan T, Li M, Yao Y, Jia J, Yi H, et al. Enhancement of sensitivity to chemo/radiation therapy by using mir- $15 \mathrm{~b}$ against dclk1 in colorectal cancer. Stem cell reports. 2018;11(6):1506-22.

9. Li L, Jones K, Mei H. Doublecotin-like kinase 1 increases chemoresistance of colorectal cancer cells through the antiapoptosis pathway. BioRxiv. 2019:517425.
10. Ge Y, Weygant N, Qu D, Houchen C. 140P DCLK1 as part of EMT feedback-loop promotes colorectal cancer cell proliferation, invasion, and 5-Fu resistance. Ann Oncol. 2018;29(suppl_9):mdy431. 051 .

11. Chandrakesan P, May R, Weygant N, Qu D, Berry WL, Sureban $\mathrm{SM}$, et al. Intestinal tuft cells regulate the ATM mediated DNA damage response via Dclk1 dependent mechanism for crypt restitution following radiation injury. Sci Rep. 2016;6:37667.

12. Weygant N, Qu D, Berry WL, May R, Chandrakesan P, Owen DB, et al. Small molecule kinase inhibitor LRRK2-IN-1 demonstrates potent activity against colorectal and pancreatic cancer through inhibition of doublecortin-like kinase 1. Mol Cancer. 2014;13(1):103.

13. Chandrakesan P, Weygant N, May R, Qu D, Chinthalapally HR, Sureban SM, et al. DCLK1 facilitates intestinal tumor growth via enhancing pluripotency and epithelial mesenchymal transition. Oncotarget. 2014;5(19):9269.

14. Park S-Y, Kim J-Y, Choi J-H, Kim J-H, Lee C-J, Singh P, et al. Inhibition of LEF1-mediated DCLK1 by niclosamide attenuates colorectal cancer stemness. Clin Cancer Res. 2019;25(4):1415-29.

Publisher's Note Springer Nature remains neutral with regard to jurisdictional claims in published maps and institutional affiliations. 